\title{
Simulação por ENVI-met das Condições Higrotérmicas da Universidade de Cuiabá, Campus Barão
}

\section{ENVI-met Simulation of Hygrothermal Conditions of University of Cuiabá, Barão Campus}

\author{
Jonathan Willian Zangeski Novais*a; Silvia Finger Dalmaso ${ }^{\mathrm{a}}$; Roberta Daniela de Souza ${ }^{\mathrm{a}}$; Naara Soares dos Santos Brito ${ }^{\mathrm{b}}$
}

aUniversidade de Cuiabá, Programa de Pós-Graduação Stricto Sensu em Ciências Ambientais. MT, Brasil.

bUniversidade de Cuiabá. MT, Brasil

*E-mail: jonathan.novais@kroton.onmicrosoft.com

\begin{abstract}
Resumo
O crescimento mal planejado das grandes cidades acarreta o aparecimento das chamadas ilhas de calor urbano, que consequentemente geram desconforto nos cidadãos. Em um contexto universitário, o desconforto térmico pode prejudicar a concentração e desempenho de alunos, professores e funcionários. Assim simulou-se o microclima da Universidade de Cuiabá, campus Barão, com o objetivo de analisar as partes críticas desconfortáveis do campus e sugerir estratégias que possam melhorar o conforto térmico local. Para a simulação utilizou-se o software ENVI-met, que espacializa as variáveis temperatura do ar e umidade relativa do ar, sendo simulados os horários de 08,14 e 20 horas no período chuvoso e seco, conforme a sazonalidade climática local. Encontrou-se como zonas críticas a entrada do Campus, Bloco A, a área de convivência nos intervalos dos alunos e o estacionamento, atingindo temperaturas máximas de $34{ }^{\circ} \mathrm{C}$. Outra questão que causa preocupação é a baixa umidade relativa do ar no período seco, em que as 14 horas chegou a mínima $23 \%$. Conclui-se que a intensificação de áreas verdes no campus, como gramados e arborização, a substituição de pavimentos, substituindo parte da área asfáltica por pavimentos de calor específico menor, e a utilização de telhado verde, podem contribuir para a melhoria do conforto térmico do campus.
\end{abstract}

Palavras-chave: Conforto Térmico. Temperatura do Ar. Umidade Relativa do Ar. Telhado Verde. Arborização.

\begin{abstract}
The poorly planned growth of large cities leads to the appearance of the so-called urban heat islands, which consequently generate discomfort for citizens. In a university context, thermal discomfort can impair the concentration and performance of students, teachers and staff. Thus, the microclimate of University of Cuiabá, Barão campus was simulated, with the objective of analyzing the uncomfortable critical parts of the campus and suggesting strategies that can improve the local thermal comfort. For the simulation, the ENVI-met software was used, which spatializes the variables air temperature and relative air humidity, simulating the times of 08,14 and 20 hours in the rainy and dry period, according to the local climatic seasonality. Critical areas were the entrance to Campus, Block A, the living area in the students'break time and the parking, reaching maximum temperatures of $34^{\circ} \mathrm{C}$. Another issue that causes concern is the low relative air humidity in the dry period, when the 14 hours reached a minimum $23 \%$. It is concluded that the green areas intensification at the campus, such as lawns and afforestation, the replacement of pavements, replacing part of the asphalt area with pavements with lower specific heat, and the use of a green roof, can contribute to the improvement of the campus thermal comfort.
\end{abstract}

Keywords: Thermal Comfort. Air Temperature. Green Roof. Afforestation.

\section{Introdução}

O deslocamento populacional das zonas rurais e pequenos municípios para cidades maiores das últimas décadas no Brasil resultaram em um crescimento urbano desordenado e em proporção inversa à sua capacidade administrativa de planejar (MONTEIRO E MENDONÇA, 2009).

Além disso, a expansão urbana atua como agente transformador da paisagem natural em um ambiente construídos, acarretando impactos negativos como o aumento e armazenamento de calor sensível devido a substituição da coberta natural do solo por superfícies impermeáveis e não evaporativas como asfalto, concreto e metal, criando condições climáticas particulares a estas áreas, entendidas como (micro)clima urbano (GAGO et al., 2013; DENG; WU, 2013; MONTEIRO; MENDONÇA, 2015).

Outros pesquisadores enfatizam ainda que as propriedades físicas dos materiais urbanos modificando a temperatura, direção e a velocidade dos ventos, além de alterar reflexão da radiação solar incidente acarreta na absorção térmica por longos períodos que contribui tanto para elevação da temperatura do ar como também para geração de ilhas de calor conhecidas também como ICU (STEWART;OKE, 2012; MONTEIRO; MENDONÇA, 2015; SYNNEFA;SANTAMOURIS, 2016).

Kruger et al. (2011) reitera que a formação de ICU não se abstém apenas à diminuição de áreas verdes nas cidades, outros fatores como tamanho das cidades, geometria das ruas e dos prédios podem intensificar sua formação.

Além disso outros impactos negativos podem ser atribuídos a ICU como aqueles relacionados a saúde da população devido ao desconforto térmico, como também, econômicos devido ao aumento do consumo de energia elétrica por climatizadores de ambientes, principalmente em regiões de clima quente como é o caso da capital de Mato Grosso, Cuiabá, conhecida 
como uma das capitais mais quentes do Brasil, não sendo raro o alcance dos $40^{\circ} \mathrm{C}$, o que contribui com a sensação de desconforto térmico tanto em ambientes externos quanto em ambientes internos (SILVA; SOUZA; NOVAIS, 2019).

Dessa forma no contexto universitário, a questão do conforto térmico torna-se relevante, uma vez que a exposição excessiva de indivíduos ao calor gera a elevação da temperatura do corpo, sonolência, estresse térmico, sobrecargas fisiológicas, lesões térmicas sérias, síncope e risco de morte (CAMARGO; FURLAN, 2011; ALAHMER et al., 2011).

Assim, visando saúde e bem-estar da população, é essencial a busca de melhorias na elaboração de projetos de condomínios, repartições, empreendimentos comerciais, loteamentos e bairros desde a sua concepção tendo como enfoque principal a qualidade de vida.

Diante dessa preocupação, estudos com metodologias distintas estabelecem uma relação benéfica entre o aumento das áreas verdes urbanas e a redução da temperatura do ar local (TAKEBAYASHI; MORIYAMA, 2007), sendo esta uma estratégia possível e efetiva de mitigação dos efeitos da ICU. No entanto, o grande desafio é tornar possível a ampliação dessas áreas em um ambiente urbano já consolidado.

A este respeito, uma alternativa é a adaptação de superfícies construídas em paredes e telhados verdes originando múltiplos benefícios, contribuindo tanto para a redução dos efeitos da ICU, como também para melhoria da qualidade do ar, gestão de águas pluviais, aumento da biodiversidade e no conforto do pedestre (OBERNDORFER et al., 2007). Akbari, Levinson e Rainer (2005) e Saiz et al. (2006) complementam ainda que os telhados constituem cerca de 20 a $25 \%$ da superfície urbana e que sua utilização para este fim contribui para redução de ruído e do consumo energético da construção, especialmente durante o verão.

Assim, na busca por um melhor entendimento das interações entre as tipologias urbanas e o microclima local pesquisadores trabalham no desenvolvimento de modelos que encontrem suas bases em fatores meteorológicos ou em características genéricas da estrutura urbana (KARATASOU; SANTAMOURIS; GEROS, 2006). Dentre eles destaca-se software ENVI-met, que se trata de um modelo tridimensional, não hidrostático, que foi criado por Michael Bruse como parte de sua tese de doutorado, realizada na Alemanha (BRUSE, 2008).

O software ENVI-met trata-se de um modelo tridimensional que simula o microclima urbano por meio das interações entre superfície-vegetação atmosfera. De acordo com Bruse (2008), o cálculo do balanço de energia é feito por meio das variáveis radiação, reflexão e sombreamento de edifícios e vegetação, fluxo do ar, temperatura, umidade, turbulência local e sua taxa de dissipação e as trocas de água e calor dentro do solo. Para Silva (2013), o ENVI-met é uma ferramenta simplificada que oferece diversos formatos de saídas, como mapas e gráficos autoexplicativos, com resultados e precisão satisfatória.

Isto posto, o estudo teve como objetivo simular as condições higrotérmicas da Universidade de Cuiabá-UNIC, campus Barão, utilizando o software ENVI-met, de modo a contribuir com possíveis estratégias de melhoria do conforto térmico para os frequentadores do campus.

\section{Material e Métodos}

\subsection{Caracterização da área de estudo}

A capital do estado de Mato Grosso, Cuiabá, pertence à região Centro-Oeste do Brasil, coordenadas geográficas - 15³5'56 latitude Sul e 56 $06^{\circ} 01$ longitude Oeste. O município possui uma área de $3.224,68 \mathrm{~km}^{2}$, sendo dividida em $254,57 \mathrm{~km}^{2}(7,89 \%)$ de área urbana e $2.970,11 \mathrm{~km}^{2}(92,1 \%)$ de área rural (IBGE, 2010). Conforme a classificação de Koppen, o município possui clima do tipo Aw, apresentando duas estações bem definidas, uma seca de abril a outubro e outra chuvosa de novembro a março (ALVARES et al., 2013).

Neste contexto, encontra-se localizada a área de realização do experimento (Figura1), na qual abrange a Universidade de Cuiabá - UNIC, Campus Barão.

Figura 1 - Localização geográfica da Universidade de Cuiabá UNIC, Campus Barão no município de Cuiabá, MT, Brasil

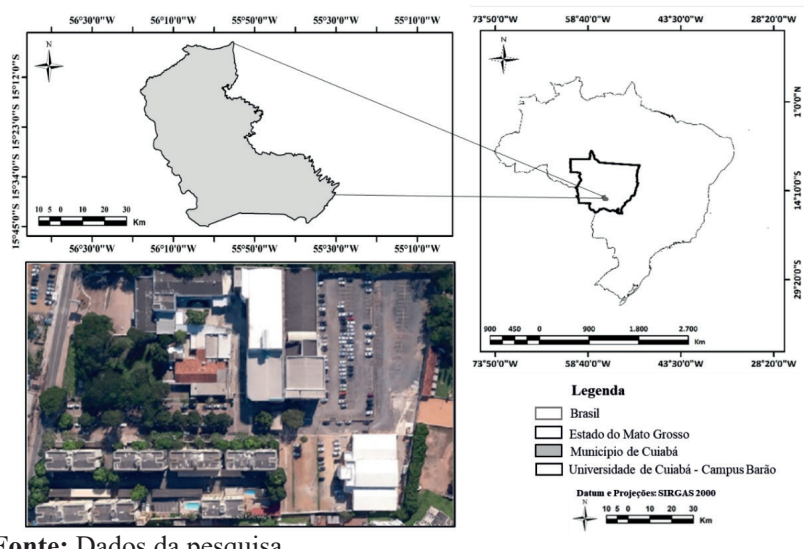

Fonte: Dados da pesquisa.

O Campus Universitário possui uma área total de $26.033,57 \mathrm{~m}^{2}$, subdivididos em duas unidades, sendo a Unidade I com área de $2.819,15 \mathrm{~m}^{2}$, correspondente ao bloco E, e, a Unidade II com área construída de 8.790,48 $\mathrm{m}^{2}$, correspondente aos blocos A, B, C, D, além de demais áreas pertinentes ao estacionamento e de uso comum. Ademais, o ambiente possui características de uso e ocupação do solo diversificadas, composto por áreas de vegetação pontual, de solo exposto, pavimentadas e áreas construídas constituídas por prédios de alvenaria com coberturas de telhas de fibrocimento. Já o estacionamento, setor superior direito é composto de pavimento asfáltico de betume espesso, e o pátio localizado entre os prédios da parte superior central é pavimentado com cimento.

\subsection{Simulação Termohigrométrica}

Como parâmetros de entrada atmosférica e validação do 
modelo, foram utilizados os dados de temperatura do ar e umidade relativa do ar do município de Cuiabá, empregues no arquivo de entrada para realização das simulações térmicas do software ENVI-met, foram obtidas na plataforma BDMEP (Banco de Dados Meteorológicos para Ensino e Pesquisa) do Instituto Nacional de Meteorologia (INMET, 2003) disponibilizadas para consulta pública e download. Foram utilizados o conjunto de dados para um dia representativos do clima do munícipio de Cuiabá em períodos distintos do ano de 2019, no período chuvoso optou-se pelo mês de janeiro e no período seco o mês junho (Quadro 1).

Quadro 1 - Valores médios horários de temperatura do ar e umidade relativa do ar - INMET

\begin{tabular}{|l|c|c|c||c|c|c|}
\hline Valores médios de temperatura do ar e umidade relativa do \\
ar - INMET \\
\hline \multicolumn{7}{|c|}{ Período do Ano } \\
\hline \multicolumn{1}{|c|}{ Horário } & \multicolumn{2}{|c|}{ Período Chuvoso } & \multicolumn{4}{c|}{ Período Seco } \\
\cline { 2 - 7 } \cline { 5 - 7 } & $08: 00$ & $14: 00$ & $20: 00$ & $08: 00$ & $14: 00$ & $20: 00$ \\
\hline $\begin{array}{l}\text { Temperatura } \\
\text { do ar }\left({ }^{\circ} \mathrm{C}\right)\end{array}$ & 25 & 34 & 27 & 30 & 34 & 27 \\
\hline $\begin{array}{l}\text { Umidade } \\
\text { relativa do ar } \\
(\%)\end{array}$ & 87 & 62 & 66 & 30 & 26 & 56 \\
\hline
\end{tabular}

Fonte: Dados da pesquisa.

A posição da área simulada está rotacionada aproximadamente 30 graus do Norte geográfico, sendo feitos grids em área e altura, em que cada grid tem $1 \mathrm{~m}^{3}$, totalizando 220 grids no eixo X, 152 grids no eixo Y, e 16 grids no eixo Z (altura).

As simulações totalizam 24 horas cada, porém sendo apresentados 3 horários que melhor demonstram a variabilidade microclimática diária e coincidindo com a presença de pessoas no campus, dessa forma os horários foram matutino às 08:00 (horário de entrada dos alunos), vespertino às 14:00 (horário mais quente do dia) e noturno às 20:00 (horário de maior fluxo de alunos no Campus), nos períodos seco e chuvoso.

\section{Resultados e Discussão}

As imagens geradas pelas simulações microclimáticas no software ENVI-MET na área de estudo no período chuvoso, estão representadas pelos mapas de temperatura do ar $\left({ }^{\circ} \mathrm{C}\right)$ e umidade relativa do ar (\%) para os horários 08:00, 14:00 e 20:00, e, comparados aos dados climáticos estimados do INMET (Quadro 1) foi possível identificar similaridade entre os valores.

Nas simulações Termohigrométrica do período chuvoso visualizadas na figura 3 , as 08:00 horas da manhã, a temperatura do ar no campus variou entre $22,4{ }^{\circ} \mathrm{C}$ e $24,4{ }^{\circ} \mathrm{C}$, valores próximos foram observados para temperatura média atmosférica para horário, $5{ }^{\circ} \mathrm{C}$. No respectivo horário, a umidade relativa do ar variou entre $80,4 \%$ e $88,5 \%$, ao passo que a umidade relativa média do ar atmosférico foi $87 \%$.
Figura 2 - Mapas de temperatura do ar $\left({ }^{\circ} \mathrm{C}\right)$ e umidade relativa do ar (\%) às 08:00 horas do período chuvoso, na Universidade de Cuiabá-UNIC, Campus Barão
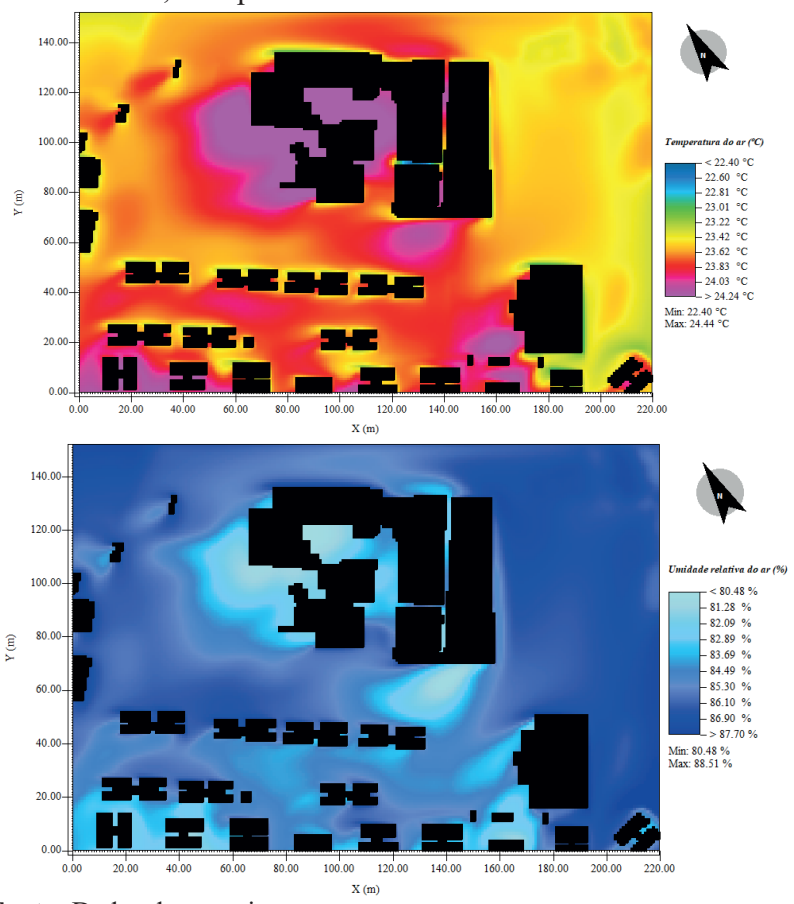

Fonte: Dados da pesquisa.

As 14 horas (horário de maior aquecimento, Figura 3) a temperatura do ar no campus variou entre $28{ }^{\circ} \mathrm{C}$ e $33,9^{\circ} \mathrm{C}$, valores próximos foram observados para temperatura média atmosférica para horário $34^{\circ} \mathrm{C}$. No respectivo horário, a umidade relativa do ar variou entre $56,9 \%$ e $62,3 \%$, ao passo que a umidade relativa média do ar atmosférico foi $62 \% .7$

Figura 3 - Mapas de temperatura do ar $\left({ }^{\circ} \mathrm{C}\right)$ e umidade relativa do ar (\%) às 14:00 horas do período chuvoso, na Universidade de Cuiabá-UNIC, Campus Barão
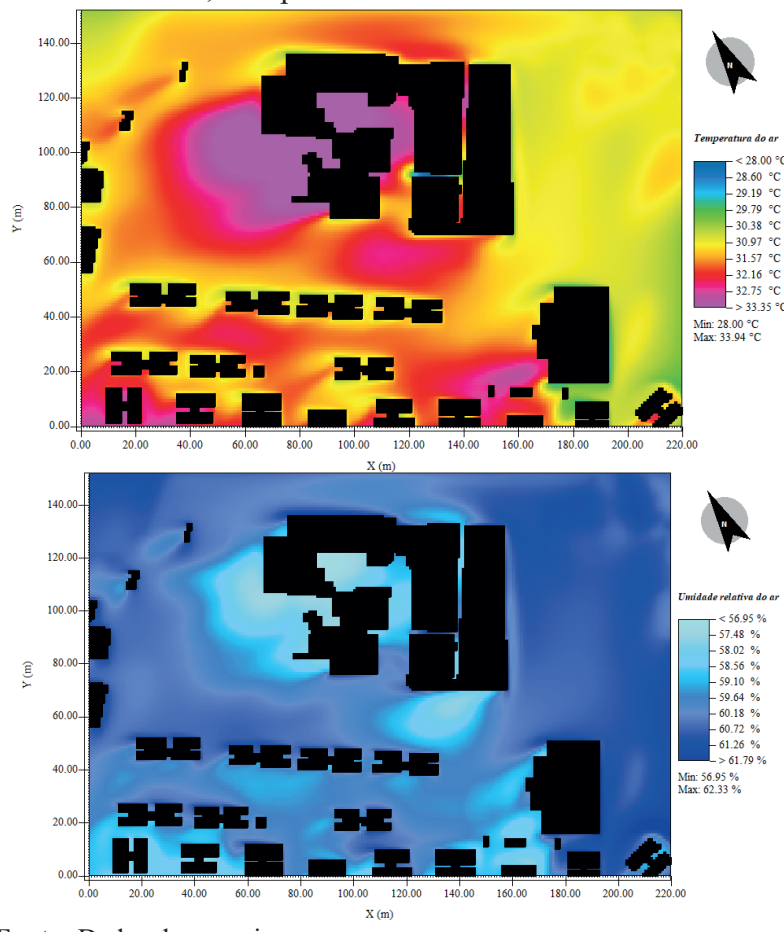

Fonte: Dados da pesquisa. 
No horário noturno, 20:00 horas (início do resfriamento, Figura 4), a temperatura do ar variou entre $24,1{ }^{\circ} \mathrm{C}$ e $27,2{ }^{\circ} \mathrm{C}$, valores próximos foram observados para temperatura média atmosférica para horário $27{ }^{\circ} \mathrm{C}$. No respectivo horário, a umidade relativa do ar variou entre $58,9 \%$ e $67,7 \%$, ao passo que a umidade relativa média do ar atmosférico foi $66 \%$.

Figura 4 - Mapas de temperatura do ar $\left({ }^{\circ} \mathrm{C}\right)$ e umidade relativa do $\operatorname{ar}(\%)$ às 20:00 horas do período chuvoso, na Universidade de Cuiabá-UNIC, Campus Barão
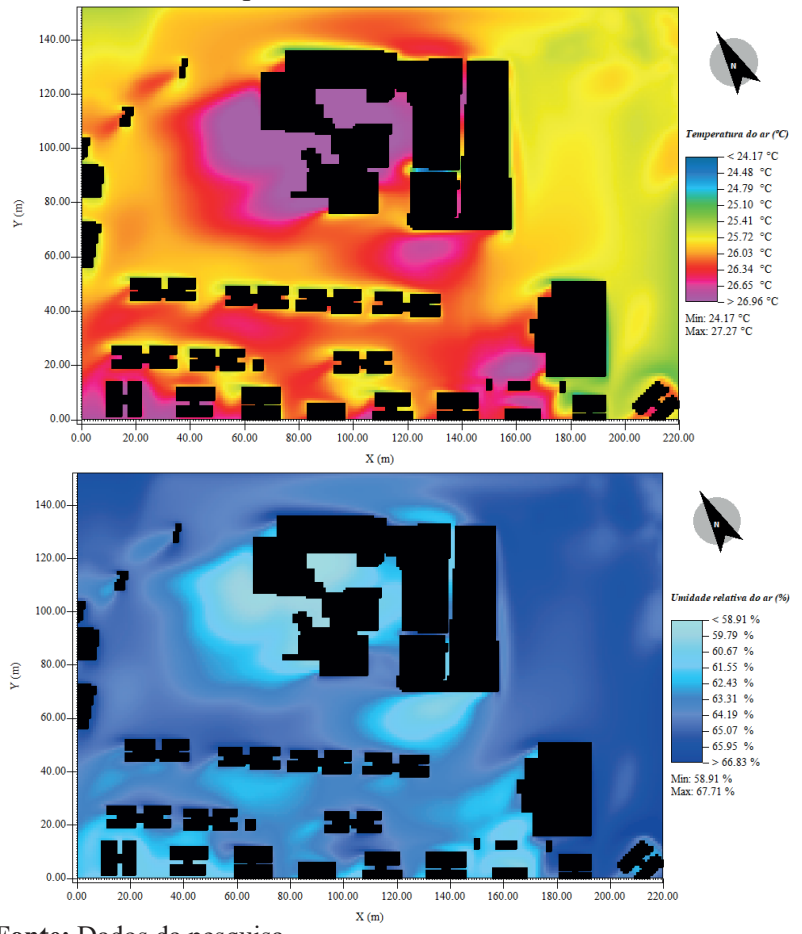

Fonte: Dados da pesquisa.

A temperatura do ar seguiu o padrão da radiação solar, ou seja, pela manhã são identificadas as menores temperaturas, as maiores são atingidas às 14:00 e vão diminuindo ao iniciar da noite (BLAIR, 1964).

Quanto ao período seco, as imagens geradas pelas simulações microclimáticas no estão representadas pelos mapas de temperatura do ar $\left({ }^{\circ} \mathrm{C}\right)$ e umidade relativa do ar (\%) para os horários 08:00, 14:00 e 20:00, e buscou-se por similaridades aos dados climáticos do INMET (Quadro 1).

Segue abaixo os resultados da temperatura do ar e umidade relativa do ar para as 8 horas da manhã do período seco.

Figura 5 - Mapas de temperatura do ar $\left({ }^{\circ} \mathrm{C}\right)$ e umidade relativa do ar (\%) às 08:00 horas do período seco, na Universidade de Cuiabá-UNIC, Campus Barão

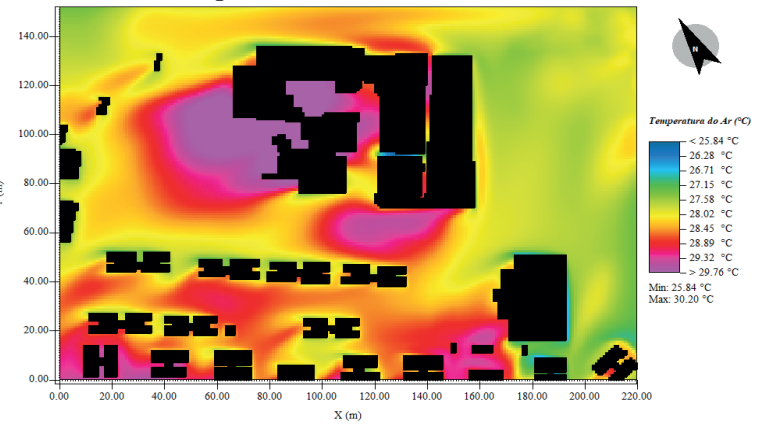

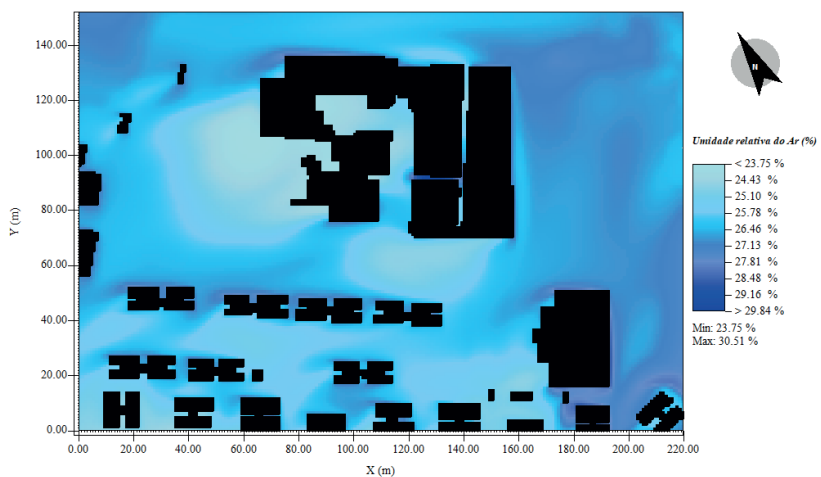

Fonte: Dados da pesquisa.

As 08:00 horas da manhã do período seco (Figura 5), a temperatura do ar no campus variou entre $25,8^{\circ} \mathrm{C}$ e $30,2{ }^{\circ} \mathrm{C}$, valores próximos foram observados para temperatura média atmosférica para horário, $30^{\circ} \mathrm{C}$. No respectivo horário, a umidade relativa do ar variou entre $23,7 \%$ e $30,5 \%$, ao passo que a umidade relativa média do ar atmosférico foi $30 \%$.

Figura 6- Mapas de temperatura do $\operatorname{ar}\left({ }^{\circ} \mathrm{C}\right)$ e umidade relativa do ar (\%) às 14:00 horas do período seco, na Universidade de Cuiabá-UNIC, Campus Barão
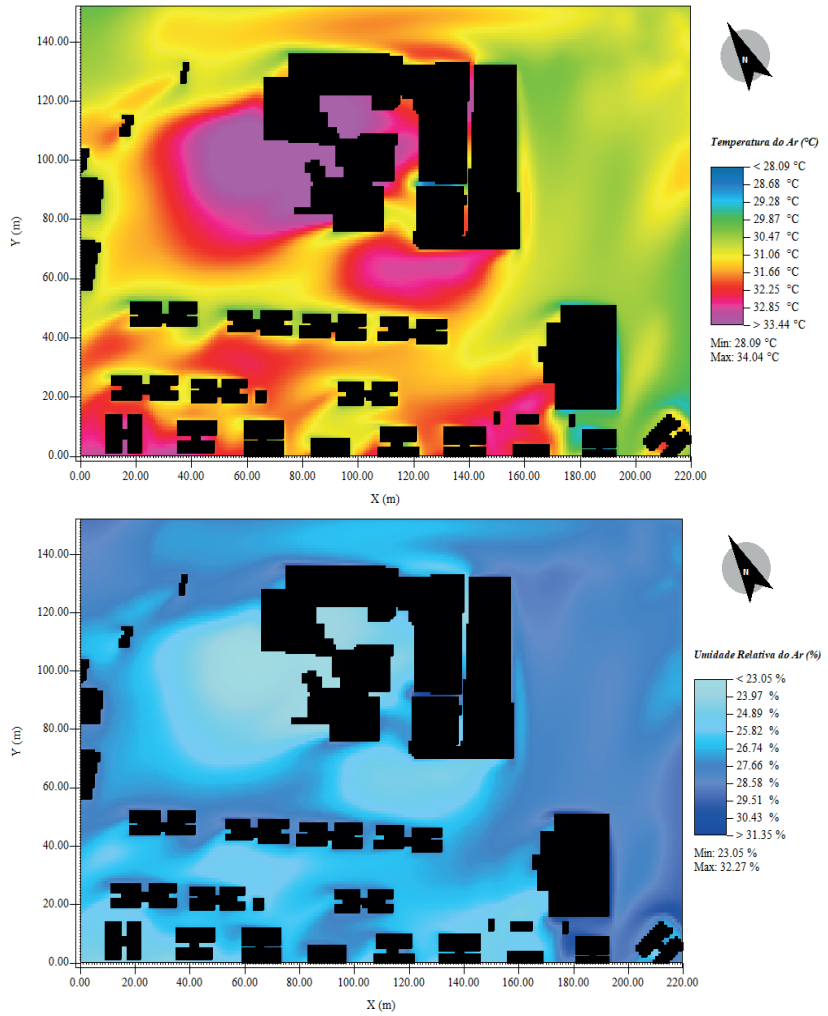

Fonte: Dados da pesquisa.

As 14 horas (Figura 6), a temperatura do ar no campus variou entre $28,0^{\circ} \mathrm{C}$ e $34,0^{\circ} \mathrm{C}$, valores próximos foram observados para temperatura média atmosférica para horário $34^{\circ} \mathrm{C}$. No respectivo horário, a umidade relativa do ar variou entre $23,0 \%$ e $32,2 \%$, e umidade relativa média do ar atmosférico foi $26 \%$. 
Figura 7 - Mapas de temperatura do ar $\left({ }^{\circ} \mathrm{C}\right)$ e umidade relativa do $\operatorname{ar}(\%)$ às 20:00 horas do período seco, na Universidade de Cuiabá-UNIC, Campus Barão

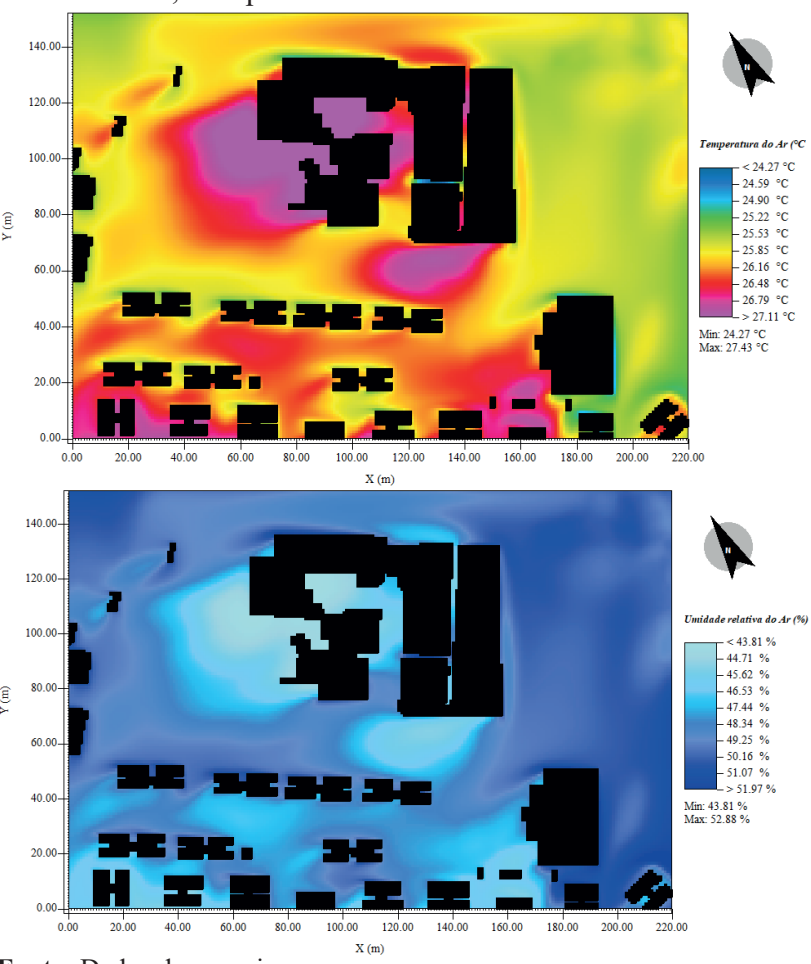

Fonte: Dados da pesquisa.

No horário noturno, 20:00 horas (Figura 7) houve um declínio da temperatura do ar que variou entre $24,2{ }^{\circ} \mathrm{C}$ e 27,4 ${ }^{\circ} \mathrm{C}$, valores próximos foram observados para temperatura média atmosférica para horário $27^{\circ} \mathrm{C}$. No respectivo horário, a umidade relativa do ar variou entre $43,8 \%$ e $52,8 \%$, ao passo que a umidade relativa média do ar atmosférico foi $56 \%$.

Constatou-se também em ambos os períodos do ano, que os maiores valores de umidade relativa do ar observados correspondem aos menores valores de temperatura do ar e viceversa, isto ocorre devido ao fato que, quando a temperatura diminui, a quantidade de vapor de água no ar não muda, mas a umidade relativa do ar aumenta (BUTERA, 1995).

Assim como no período chuvoso observou-se a elevação da temperatura do ar de maneira gradual entre o final da manhã e no decorrer das primeiras horas da tarde, decaindo ao anoitecer.

$\mathrm{Na}$ análise de ambos os períodos do ano foram detectadas zonas de calor intenso, com máximas simuladas de $34{ }^{\circ} \mathrm{C}$, nas imediações da entrada do campus universitário, nas proximidades do Bloco A (área de uso comum), na área de lazer e convivência dos alunos em que fica a cantina e na região da guarita que dá acesso ao estacionamento do campus. Tais áreas possuem em seu entorno aglomerados de edificações correspondentes aos blocos A, B, C, que impedem a adequada circulação do ar e a ventilação natural e impossibilitando a dissipação do calor que fica concentrado corroborando para formação de ilhas de calor pontuais.

Outro fator de influência é a proximidade com a Avenida Barão de Melgaço, que possui intenso fluxo de veículo contribuindo para aumento a temperatura do ar, pois, conforme afirmado por Gartland (2010), superfícies constituídas por asfalto, normalmente, apresentam temperaturas elevadas se comparadas aos outros materiais. Maciel (2014) reitera que este efeito é explicado pelo baixo valor de albedo deste material, que resulta em grande absorção da energia térmica proveniente da radiação solar.

Outra área de calor detectada refere-se ao estacionamento, que é acometida por grande incidência de radiação solar devido à ausência de vegetação, contribuindo para o aumento da temperatura do ar, uma vez que, o asfalto betuminoso absorve grande parte dessa energia acumulando e transmitindo para o meio em forma de calor. Leal (2012) explica que, materiais construtivos como o concreto, a cerâmica, os tijolos e o asfalto têm boa condutibilidade, criando condições propícias para o aquecimento.

Andrade et al. (2016) mencionam que as construções e os veículos contribuem para acelerar o aquecimento das cidades através do calor dissipado pela atmosfera e que esse índice pode representar um terço da energia solar incidida e, cabe considerar a grande área de espaços pavimentados no ambiente urbano.

Novais et al. (2016) em estudo realizado na mesma localidade, encontraram temperaturas máximas de superfície para o asfalto do estacionamento de até $63{ }^{\circ} \mathrm{C}$, explicando que essa alta absorção de calor ocorre pelo seu alto calor específico, aproximadamente $0,223 \mathrm{cal} / \mathrm{g}{ }^{\circ} \mathrm{C}$, levando um maior tempo para liberá-lo. A substituição de parte desse pavimento por superfícies de cores mais claras, ou áreas gramadas, que possuam calor específico menor, podem melhorar o conforto térmico do local.

Ressalta-se que, mediante a extensão do campus universitário algumas adequações poderiam ser realizadas visando o conforto e o bem-estar, como por exemplo a adoção de telhado verde. De acordo com Andrade et al. (2013), em estudo para Cuiabá-MT foram observadas diferenças maiores que $2{ }^{\circ} \mathrm{C}$ para simulações com telhado verde. Outra consequência é a melhoria do ambiente interno, trazendo benefícios inclusive na aprendizagem dos alunos, em que Elali (2003), afirma que o conforto térmico influencia em fatores como como a sociabilidade dos usuários, seu desempenho acadêmico e consequentemente em sua saúde.

Matheus et al. (2016), em estudo que comparou telhado verde e telhas cerâmicas, mostrou que o telhado verde acarreta um atraso térmico de 2 horas no interior da edificação, demorando mais para esquentá-la, e uma diminuição de temperatura interior que pode chegar a aproximadamente $9{ }^{\circ} \mathrm{C}$ nos horários mais quentes do dia.

Outra medida benéfica seria o plantio de mudas arbóreas no estacionamento, pois estas interceptam, refletem, absorvem e transmitem a radiação solar, sendo fundamental para garantir conforto térmico em climas tropicais úmidos. 


\section{Conclusão}

De acordo com os resultados encontrados pela simulação observou-se que as variações horárias térmicas acompanharam o padrão solar, e que em ambas simulações o período seco teve maiores temperaturas do ar que o chuvoso, destacando-se a temperatura máxima de $34^{\circ} \mathrm{C}$ e umidade relativa mínima de $23 \%$, ambas ocorrendo no período seco as 14 horas.

Encontrou-se como zonas críticas a entrada do Campus, Bloco A, a área de convivência nos intervalos dos alunos e o estacionamento, A intensificação de áreas verdes no campus, como gramados e arborização, a substituição de pavimentos, substituindo parte da área asfáltica por pavimentos de calor específico menor, e a utilização de telhado verde podem contribuir para a melhoria do conforto térmico do campus.

\section{Referência}

AKBARI, H.; LEVINSON, R.; RAINER, L. Monitoring the energy-use effects of cool roofs on California commercial buildings. Energy Buildings, v.37, n.10, p.1007-1016, 2005.

ALAHMER, A. et al. Vehicular thermal comfort models; a comprehensive review. Appl. Thermal Engineering, v.31, n.6-7, p.995-1002, 2011.

ALVARES, C.A. et al. Modeling monthly mean air temperature for Brazil. Theoretical Appl. Climatol., v.113, n.3/4, p.407-427. 2013.

ANDRADE, L.P. et al. Efeitos de borda sobre o microclima de um parque ecológico urbano em Cuiabá-MT. Estudo \& Debate, v.23, n.2, 2016. doi: http://dx.doi.org/10.22410/issn.1983-036X. v23i2a2016.1078

BLAIR, T A. Meteorologia. Rio de Janeiro: Ao Livro Técnico, 1964.

BRUSE, M.; FLEER, H. Simulating surface-plant-air interactions inside urban environments with a three dimensional numerical model. Environmental Modelling \& Software, v.13, n.3/4, p. 373-384, 1998.

BUTERA, F. Architettura e ambiente. Manuale per il controllo della qualità termica, luminosa e acustica degli edifici. Milano: Etas libri, 1995.

CAMARGO, M.G.; FURLAN, M.M.D.P. Resposta fisiológica do corpo às temperaturas elevadas: exercício, extremos de temperatura e doenças térmicas. Saúde Pesq., v.4, n.2, 2011.

DENG, C.; WU, C. Examining the impacts of urban biophysical compositions on surface urban heat island: A spectral unmixing and thermal mixing approach. Remote Sensing Environ., v.131, p.262-274, 2013.

ELALI, G.A. O ambiente da escola-o ambiente na escola: uma discussão sobre a relação escola-natureza em educação infantil. Estud. Psicol., v.8, n.2, p.309-319, 2003.

GAGO, E. J.; PACHECO TORRES, R.; ETXEBARRÍA B. S. The city and urban heat islands: A review of strategies to mitigate adverse effects. Renewable Sustainable Energy Rev., v.25, p.749$758,2013$.
GARTLAND, L. Ilhas de calor: como mitigar zonas de calor em áreas urbanas. São Paulo: Oficina de Textos, 2011.

IBGE. Instituto Brasileiro de Geografia e Estatística. Censo Demográfico. 2010. Disponível em: $<$ https://cidades.ibge.gov.br/ xtras/perfil.php?cod m u n =510340>. Acesso em: 14 jun. 2020.

INMET - Instituto Nacional de Meteorologia. Climatologia. 2003. Disponível em: $<\mathrm{http}: / / \mathrm{www}$.inmet.gov.br/html/clima. php>. Acesso em: 8 mar. 2020.

KARATASOU, S.; SANTAMOURIS, M.; GEROS, V. Urban building climatology. Environmental design of urban buildings. Routledge, 2013. p. 119-143.

KRÜGER, E.L.; MINELLA, F.O.; RASIA, F. Impact of urban geometry on outdoor thermal comfort and air quality from field measurements in Curitiba, Brazil. Build Environment, v.46, p. $621,2011$.

LEAL, L. A influência da vegetação no clima urbano da cidade de Curitiba-PR. Curitiba: PUC, 2012.

MACIEL, C.R. Análise da relação entre características do ambiente urbano e o comportamento de variáveis microclimáticas: estudo de caso em Cuiabá-MT. Cuiabá: Universidade Federal de Mato Grosso, 2014.

MATHEUS, C. et al. Desempenho térmico de envoltórias vegetadas em edificações no sudeste brasileiro. Amb. Construído, v.16, n.1, p.71-81, 2016.

MONTEIRO, C.A.F.; MENDONÇA, F. Clima urbano. São Paulo: Contexto, 2015.

NOVAIS, J.W.Z. et al. Condições térmicas e dependência espacial da temperatura de diferentes superfícies pelo Método da Krigagem em Cuiabá-MT, Brasil. Ensaios Ciênc., v.20, n.3, p.131-136, 2016. doi: https://doi.org/10.17921/14156938.2016v20n3p133-138

OBERNDORFER, E. et al. Green roofs as urban ecosystems: ecological structures, functions, and services. BioScience, v.57, n. 10, p.823-833, 2007.

SAIZ, S. et al. Comparative life cycle assessment of standard and green roof. Environ. Scie. Technol., v.40, p.4312-4316, 2006.

SILVA, C.F.E. $O$ conforto térmico de cavidades urbanas: contexto climático do Distrito Federal. Brasília: Universidade de Brasília, 2013.

SILVA, R.D.S.L.; SOUZA, M.D.; NOVAIS, J.W.Z. Avaliação do conforto térmico no interior de um veículo automotor pertencente à frota de transporte público coletivo no município de CuiabáMT. Cuiabá: UNIC, 2019.

STEWART, I.D.; OKE, T.R. Local climate zones for urban temperature studies. Bull. Am. Meteorol. Soc., v.93, n.12, p.18791900, 2012.

SYNNEFA, A.; SANTAMOURIS, M. Mitigating the urban heat with cool materials for the building's fabric. In: SANTAMOURIS, M.; KOLOKOTSA, D. Urban Climate Mitigation Techniques. New Yok: Routledgep, 2016. p.67-91,

TAKEBAYASHI, H.; MORIYAMA, M. Surface heat budget on green roof and high reflection roof for mitigation of urban heat island. Building Environ., v. 42, n. 8, p. 2971-2979, 2007. 